\title{
Anti-IgE Therapy with Omalizumab Decreases Endothelin-1 in Exhaled Breath Condensate of Patients with Severe Persistent Allergic Asthma
}

\author{
Ziemowit Zietkowski Roman Skiepko Maria M. Tomasiak-Lozowska \\ Anna Bodzenta-Lukaszyk \\ Department of Allergology and Internal Medicine, Medical University of Bialystok, Bialystok, Poland
}

\section{Key Words}

Omalizumab · Asthma • Endothelin-1 · Exhaled breath condensate

\begin{abstract}
Background: Omalizumab is a humanized monoclonal antiIgE antibody, especially useful for the treatment of severe persistent allergic asthma, inadequately controlled despite regular therapy. Objectives: The aim of the study was to determine the effect of omalizumab treatment on changes in endothelin-1 (ET-1), which plays an important role in the development of airway inflammation and remodeling in exhaled breath condensate $(E B C)$ in patients with severe asthma. Methods: The study was conducted in a group of $19 \mathrm{pa}-$ tients with severe persistent allergic asthma treated with conventional therapy (according to the Global Initiative for Asthma, 2006) and with or without omalizumab (9 vs. 10 patients). Changes in ET-1 in EBC compared with other inflammatory parameters [exhaled nitric oxide - $\left(\mathrm{F}_{\mathrm{NO}}\right)$, blood eosinophil count, and serum eosinophil cationic protein (ECP)] were measured after 16 and 52 weeks of therapy. Results: Omalizumab-treated patients demonstrated a statistically significant decrease in the concentrations of ET-1 in EBC, $\mathrm{FE}_{\mathrm{NO}}$, serum $\mathrm{ECP}$, and blood eosinophil count and an increase in spirometry parameters compared to patients with conventional therapy. In the group of omalizumab-treated pa-
\end{abstract}

tients, statistically significant correlations between the decrease in $\mathrm{ET}-1$ in $\mathrm{EBC}$ and a decrease in $\mathrm{FE}_{\mathrm{NO}}$, $\mathrm{ECP}$, and blood eosinophil count as well as the increase in forced expiratory volume in $1 \mathrm{~s}$ after omalizumab therapy were revealed. Conclusions: Our results confirmed that anti-IgE therapy with omalizumab in patients with severe persistent allergic asthma results in decreased expression of ET-1 in the airways. This could be very important in limiting airway inflammation and bronchial structural changes caused by such treatment in asthmatic patients.

Copyright $\odot 2010$ S. Karger AG, Basel

\section{Introduction}

Asthma is characterized by airway inflammation, bronchial hyperresponsiveness, and airway remodeling. Airway remodeling is defined as structural changes in the airways, including increased airway smooth muscle mass, mucus gland hypertrophy, deposition of extracellular matrix components, thickening of the regular basement membrane and angiogenesis [1].

IgE plays an important role in allergic asthma. Mast cell activation and release of mediators in response to an allergen and IgE result in a cascade response, accumulation of of B lymphocytes, T lymphocytes, eosinophils, fibroblasts and smooth muscle cells, and epithelial and en-

\section{KARGER}

Fax +41613061234 E-Mail karger@karger.ch www.karger.com
(C) 2010 S. Karger AG, Basel

0025-7931/10/0806-0534\$26.00/0

Accessible online at:

www.karger.com/res
Z. Zietkowski, MD, PhD

Department of Allergology and Internal Medicine, Medical University of Bialystok

Sklodowska-Curie Street 24A

PL-15-276 Bialystok (Poland)

Tel. +48 85746 8373, Fax +48 85746 8601, E-Mail z.zietkowski@wp.pl 
dothelial activation. Through a number of intercellular interactions and the release of cytokines, mediators and chemokines, this process leads to intensification of airway inflammation, remodeling and symptoms of chronic asthma [2].

Omalizumab is a monoclonal anti-IgE antibody synthesized for the therapy of asthmatic patients with inadequately controlled severe persistent allergic asthma despite optimal controller treatment [3]. Omalizumab reduces serum IgE levels and FceRI receptor expression on key cells in the inflammatory cascade [4]. The consequences of these processes are inhibition of the release of inflammatory mediators from mast cells, and diminished recruitment of inflammatory cells, especially eosinophils, into the airways [4].

Endothelins are a family of peptide mediators which are involved in inflammation, fibrosis, and broncho- and vasoconstriction in human airways [5]. Endothelin-1 (ET-1) is expressed in the airway epithelial and endothelial cells and plays a role in the pathogenesis of bronchial asthma [6, 7]. It has also been suggested that ET-1 participates in asthmatic inflammation, especially in the development of severe bronchial hyperreactivity and airway remodeling, inducing the concentration and proliferation of bronchial smooth muscle cells as well as subepithelial fibrosis [8].

The mechanisms underlying the clinical and anti-inflammatory efficacy of omalizumab are not fully understood. Omalizumab reduces airway inflammation; however, so far there have only been a few clinical trials suggesting the effect of this kind of therapy on airway remodeling [9]. There are no data assessing the effect of anti-IgE treatment on ET-1 expression in the airways.

The aim of the present study was to assess changes in ET-1 concentrations in the exhaled breath condensate (EBC) of asthmatics with severe persistent allergic asthma during omalizumab therapy and to establish a possible correlation of these measurements with other parameters of airway inflammation.

\section{Material and Methods}

\section{Patients}

This open-label study study was performed on a group of 19 patients with severe persistent allergic asthma. Randomization was not performed. Nine patients were qualified to receive omalizumab therapy. Subsequently, 10 patients were qualified for conventional treatment without omalizumab, as recommended by the Global Initiative for Asthma, 2006 [10]. The authors have made every effort to make the two studied groups comparable regarding the severity and kind of asthma, spirometry parame- ters, intensity of day and night symptoms and control treatment used, as well as the necessity for rescue medication. Immunological parameters (including ET-1) were evaluated after the inclusion of patients into the studied groups.

All patients treated with omalizumab as well as those undergoing conventional treatment, used inhaled short-acting $\beta_{2}$-agonists (as rescue medication), inhaled long-acting $\beta_{2}$-agonists, and high doses of inhaled steroids and leukotriene receptor antagonists for at least 6 months in constant doses. No patient took oral steroids during at least the 2 previous months or during the study. All patients were atopic and sensitized to common inhaled allergens, as evaluated by skin prick tests; they had total serum IgE of at least $30 \mathrm{IU} / \mathrm{ml}$ to no more than $700 \mathrm{IU} / \mathrm{ml}$. All patients had been in a stable condition, free from acute exacerbation and respiratory tract infections, for the previous 2 months. They were nonsmokers, and had not been passive smokers during the past year.

All of the patients were examined by a physician, and then underwent EBC collection, exhaled nitric oxide ( $\mathrm{FE}_{\mathrm{NO}}$ ) measurement and spirometry. Blood samples were collected to determine serum total IgE, eosinophil cationic protein (ECP), and blood eosinophil count. All measurements were performed before, after 16 and 52 weeks of treatment. On the basis of clinical assessment of treatment efficacy [day and night symptom score, rescue salbutamol consumption, peak expiratory flow and forced expiratory volume in $1 \mathrm{~s}\left(\mathrm{FEV}_{1}\right)$ evaluation], 2 patients from the omalizumab-treated group were identified as nonresponders, and omalizumab treatment was thus terminated after 16 weeks.

Patients were treated with omalizumab on the basis of the concentration of serum total IgE and patient body weight at baseline [11].

The study protocol was approved by the Research Ethics Committee of the Medical University of Bialystok (agreement No. R-I002/68/2007). Informed consent was obtained from every patient entered into the study.

\section{Measurements}

$\mathrm{FE}_{\mathrm{NO}}$ was measured by the chemiluminescence technique using a Sievers 280i NO Analyzer (Boulder, Colo., USA). The measurements were performed in all of the asthmatic patients at an expiratory flow of $50 \mathrm{ml} / \mathrm{s}$ [12]. The duration of exhalation had to be at least $6 \mathrm{~s}$ to produce a stable NO level for $3 \mathrm{~s}$. All subjects had three $\mathrm{FE}_{\mathrm{NO}}$ recordings. Repeated measurements were performed until the 3 values agreed within $10 \%$ of the mean. The mean value of the three measurements was recorded as the final $\mathrm{FE}_{\mathrm{NO}}$ level.

The baseline spirometry was performed using a MasterScreen Pneumo PC spirometer (Erich Jaeger GmbH, Hoechberg, Germany). Spirometry was performed according to the standards of the American Thoracic Society [13]. FEV 1 was evaluated. Before the examination, the patients did not take any medications that could change spirometry results. The highest value from three technically satisfactory attempts was recorded.

EBC was collected by using a commercially available condenser (EcoScreen; Erich Jaeger $\mathrm{GmbH}$ ) according to current American Thoracic Society/European Respiratory Society guidelines [14]. All measurements were performed at the same time (between 8.00-10.00 a.m.) to avoid a possible influence of circadian rhythm on mediator concentrations in EBC. All patients were asked to refrain from eating and drinking before collection of EBC. Exhaled air entered and left the chamber through one-way valves and an inlet and outlet, thus keeping the chamber closed. Low 
Table 1. Studied patients' characteristics

\begin{tabular}{|c|c|c|c|}
\hline Characteristics & $\begin{array}{l}\text { Patients treated } \\
\text { with omalizumab }\end{array}$ & $\begin{array}{l}\text { Patients not treated } \\
\text { with omalizumab }\end{array}$ & $\begin{array}{l}\text { Differences between groups } \\
\text { of asthma patients, } \mathrm{p}\end{array}$ \\
\hline Patients, $\mathrm{n}$ & 9 & 10 & \\
\hline Sex, F/M & $1 / 8$ & $3 / 7$ & \\
\hline Age, years & $49.3 \pm 8.2$ & $52.0 \pm 8.6$ & 0.95 \\
\hline Duration of symptoms, years & $13.4 \pm 8.1$ & $15.3 \pm 12.5$ & 0.67 \\
\hline Baseline $\mathrm{FEV}_{1}, \%$ of predicted & $49.2 \pm 10.8$ & $51.4 \pm 8.8$ & 0.63 \\
\hline Blood eosinophil count, cells $/ \mathrm{mm}^{3}$ & $294.4 \pm 283.8$ & $170.3 \pm 72.8$ & 0.14 \\
\hline Baseline $\mathrm{FE}_{\mathrm{NO}}, \mathrm{ppB}$ & $59.4 \pm 46.8$ & $41.0 \pm 26.6$ & 0.30 \\
\hline Serum total IgE, kU/l & $218 \pm 123$ & $156 \pm 150$ & 0.36 \\
\hline $\mathrm{ET}-1$ (EBC), fmol/ml & $2.57 \pm 0.57$ & $2.38 \pm 0.54$ & 0.33 \\
\hline ECP (serum), $\mu \mathrm{g} / 1$ & $25.6 \pm 18.4$ & $16.6 \pm 6.1$ & 0.16 \\
\hline \multicolumn{4}{|l|}{ ICS dose } \\
\hline Before the study, $\mu \mathrm{g} /$ day & $1,138 \pm 253$ & $1,125 \pm 317$ & 0.86 \\
\hline After 52 weeks, $\mu \mathrm{g} /$ day & $1,027 \pm 195$ & $1,125 \pm 317$ & \\
\hline Positive skin prick tests (mite/cat/moulds), $n$ & $9 / 2 / 3$ & $10 / 3 / 4$ & \\
\hline
\end{tabular}

Data are presented as means \pm SD. ICS $=$ Inhaled corticosteroids (fluticasone propionate equivalent).

temperature inside the condensing chamber throughout the collection time produced a cooled-down sample. The temperature of collection was around $0^{\circ} \mathrm{C}[15]$. Patients were instructed to breathe tidally for $10 \mathrm{~min}$ with a nose clip. The respiratory rate ranged from 15 to 20 breaths/min. Patients were asked to swallow their saliva periodically and to temporarily discontinue collection if they needed to cough. At the end of collection 1.5- to $3.5-\mathrm{ml}$ aliquots of condensate were transferred to Eppendorf tubes and immediately frozen. Samples were stored at $-80^{\circ} \mathrm{C}$ [16]. The longest storage time of EBC samples did not exceed 2 months. The samples were not concentrated or lyophilized prior to measurement. All measurements were performed in a blinded fashion. All samples were run in duplicate. Because the marker used to correct the difference in the degree of dilution has not yet been established, in our study we made no attempt to assess the dilution of airway lining fluid in EBC. The results (ET-1) were well repeatable $[\mathrm{CV}(\%)=5-6 \%]$. We performed a preliminary study in which we measured ET-1 in EBC immediately after collection, and after 1, 2 , and 3 months of storage at $-80^{\circ} \mathrm{C}$ and did not observe any changes. Therefore, we suggest that ET- 1 in EBC stored at $-80^{\circ} \mathrm{C}$ remains stable for at least 3 months.

Serum total IgE concentrations and serum ECP were measured using ImmunoCAP ${ }^{\mathrm{TM}}$ Technology (Pharmacia Diagnostics, Uppsala, Sweden). The minimum detectable level of ECP was $2.0 \mu \mathrm{g} / \mathrm{l}$. Blood eosinophil count was measured using a Hematology Analyzer (Coulter Electronics Inc., Miami, Fla., USA). The concentrations of ET-1 in EBC were determined using enzyme immunoassay kits for quantitative determination (ET-1 - Biomedica Gruppe, Vienna, Austria). Detection limit (0 fmol/ml + $3 \mathrm{SD}): 0.02 \mathrm{fmol} / \mathrm{ml}$.

Analysis

As the data were normally distributed, statistical analyses were done using an analysis of variance followed by Bonferroni's post hoc t test to determine statistical differences. All values were expressed as means \pm SD; $p<0.05$ was considered significant. The correlation between studied parameters was assessed using Pearson's linear correlation coefficient.

\section{Results}

The patients' characteristics are presented in table 1. There were no statistically significant differences between any studied parameters in either group of asthmatic patients before the treatment.

In the group of patients treated with omalizumab, we found a statistically significant decrease in ET-1 levels (before therapy: $2.57 \pm 0.57 \mathrm{fmol} / \mathrm{ml}$, after 16 weeks: 2.02 $\pm 0.32, \mathrm{p}=0.004$, after 52 weeks: $1.44 \pm 0.34, \mathrm{p}=0.004$ ) (fig. 1) and $\mathrm{FE}_{\mathrm{NO}}$ (before therapy: $59.4 \pm 46.8 \mathrm{ppB}$, after 16 weeks: $31.43 \pm 18.2, \mathrm{p}=0.01$, after 52 weeks: $25.28 \pm$ 17.62, $\mathrm{p}=0.06$ ) (fig. 2). We also observed a statistically significant decrease in serum ECP (before therapy: 25.6 $\pm 18.4 \mu \mathrm{g} / \mathrm{l}$, after 16 weeks: $10.41 \pm 3.45, \mathrm{p}=0.02$, after 52 weeks: $8.07 \pm 2.59, \mathrm{p}=0.007$ ) (fig. 3) and blood eosinophil count (before therapy: $294.4 \pm 283.8$, after 16 weeks: $136.6 \pm 114.5, \mathrm{p}=0.04$, after 52 weeks: $93.5 \pm$ 81.7, $\mathrm{p}=0.18$ ) (fig. 4). In this group of patients, we also noticed an improvement of spirometric indices (statistically significant increase in $\mathrm{FEV}_{1}$ : before therapy: $49.2 \pm$ $10.8 \%$ of predicted, after 16 weeks: $61.5 \pm 10.35, \mathrm{p}=$ 0.003 , after 52 weeks: $66.14 \pm 11.9, \mathrm{p}=0.02$ ) (fig. 5). Nine 
Fig. 1. Changes in ET-1 concentrations during omalizumab (a) or conventional (b) therapy without omalizumab. Results obtained in 2 patients identified as nonresponders.
Fig. 2. Changes in $\mathrm{FE}_{\mathrm{NO}}$ levels during omalizumab (a) or conventional (b) therapy without omalizumab. ------- = Results obtained in 2 patients identified as nonresponders.
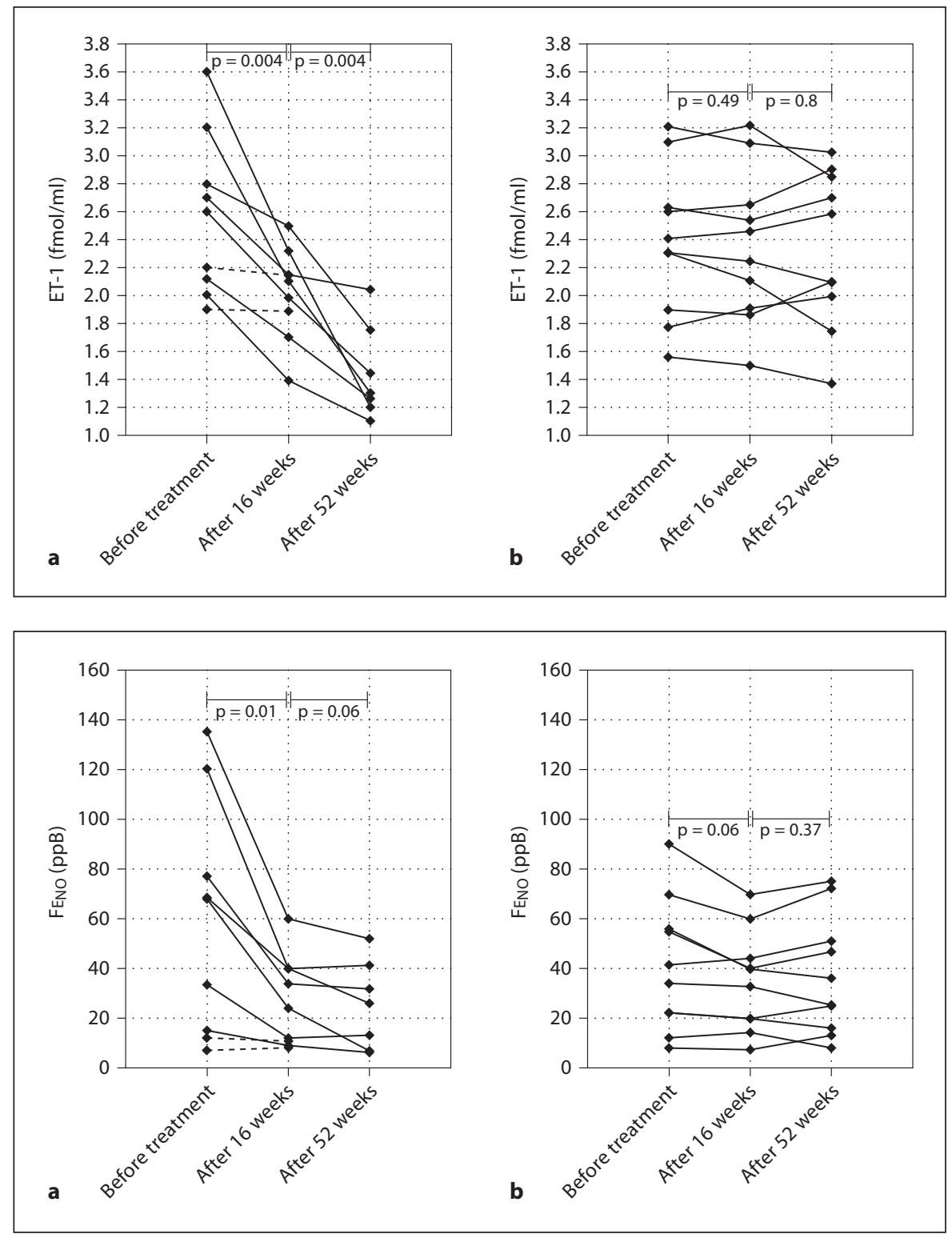

patients were assessed after 16 weeks and 7 patients after 52 weeks.

We did not observe such changes in the group undergoing conventional treatment without omalizumab (ET-1 - before therapy: $2.38 \pm 0.54 \mathrm{fmol} / \mathrm{ml}$, after 16 weeks: $2.35 \pm 0.51, \mathrm{p}=0.49$, after 52 weeks: $2.32 \pm 0.57$, $\mathrm{p}=0.8 ; \mathrm{FE}_{\mathrm{NO}}$ - before therapy: $41.0 \pm 26.6 \mathrm{ppB}$, after 16 weeks: $34.8 \pm 20.16, p=0.06$, after 52 weeks: $38.8 \pm 23.8$, $\mathrm{p}=0.37$; serum ECP - before therapy: $16.6 \pm 6.1 \mu \mathrm{g} / \mathrm{l}$, after 16 weeks: $16.3 \pm 5.68, \mathrm{p}=0.48$, after 52 weeks: 16.07 $\pm 4.7, \mathrm{p}=0.69$; blood eosinophil count - before therapy: $170.3 \pm 72.8$, after 16 weeks: $161.6 \pm 80.5, p=0.97$, after
52 weeks: $162.35 \pm 70.5, \mathrm{p}=1.0 ; \mathrm{FEV}_{1}$ - before therapy: $51.4 \pm 8.8 \%$ of predicted, after 16 weeks: $52.6 \pm 6.5, \mathrm{p}=$ 0.37 , after 52 weeks: $51.0 \pm 8.53, \mathrm{p}=0.28$ ).

In the group of patients treated with omalizumab, we found a statistically significant correlation between the decrease in ET-1 in EBC and a decrease in $\mathrm{FE}_{\mathrm{NO}}$, serum ECP and blood eosinophil count after 16 weeks of therapy. We also found a correlation between the decrease in ET-1 and an increase in $\mathrm{FEV}_{1}$ after therapy. After 52 weeks, we observed a statistically significant correlation between the decrease in ET-1 in EBC and a decrease in $\mathrm{FE}_{\mathrm{NO}}$ (table 2). These parameters were not correlated in 
Fig. 3. Changes in serum ECP concentrations during omalizumab (a) or conventional (b) therapy without omalizumab. ----- = Results obtained in 2 patients identified as nonresponders.
Fig. 4. Changes in blood eosinophil count during omalizumab (a) or conventional (b) therapy without omalizumab. Results obtained in 2 patients identified as nonresponders.
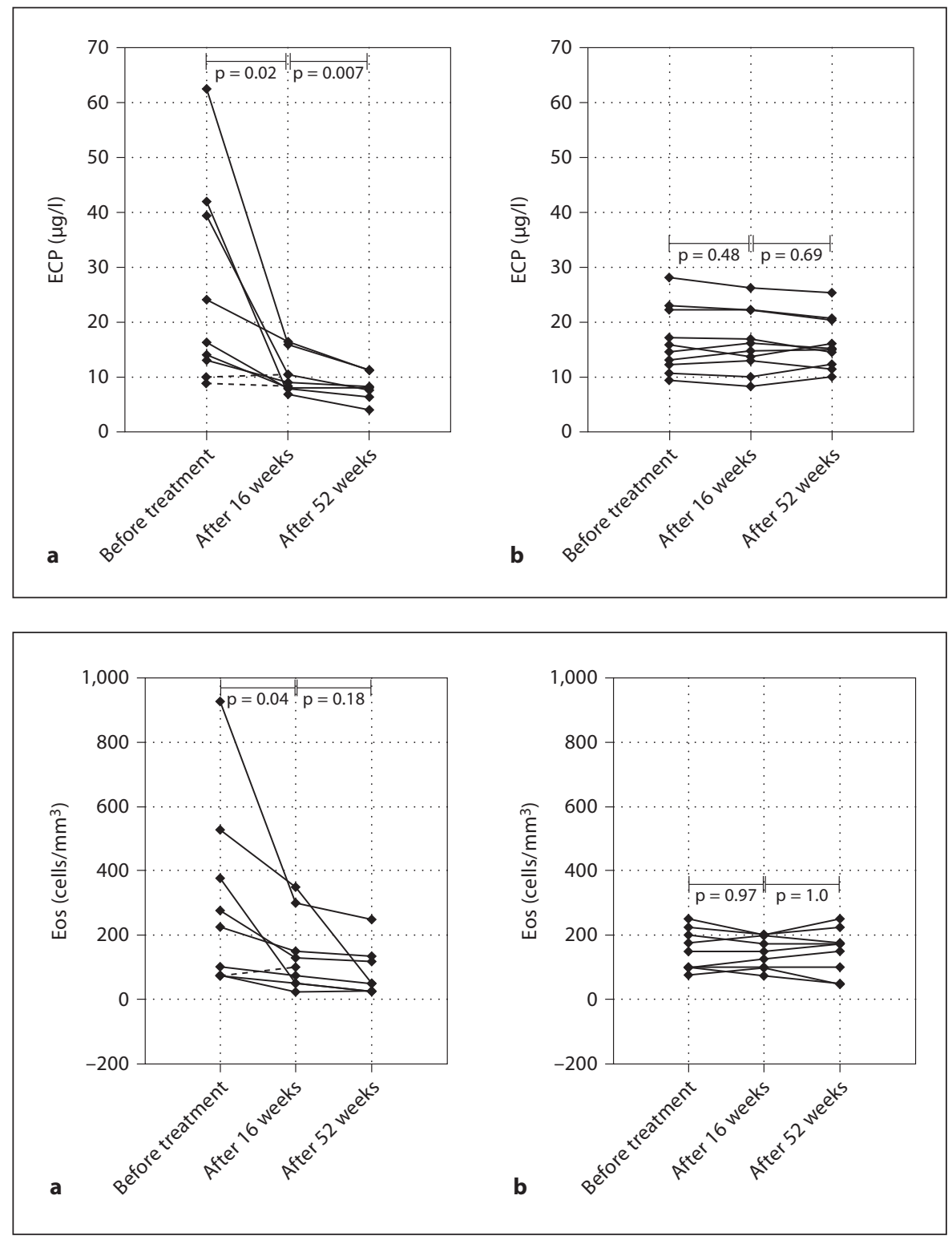

the group of patients treated without omalizumab (table 3).

Omalizumab treatment was well tolerated; we did not observe any adverse events. In the group of omalizumabtreated patients, the doses of inhaled steroids were reduced in 3 patients. There were no changes in the group treated without omalizumab. In the group of omalizumab-treated patients, exacerbations of asthma were not observed during the study. In the group of patients treated without omalizumab, exacerbations of asthma caused by respiratory tract infections, not requiring oral steroids, were observed in 4 patients. However, no patient had exacerbations or changes in antiasthmatic treatment during the 2 months prior to the assessments performed during the study (before, after 16 and after 52 weeks).

\section{Discussion}

IgE plays a key role in allergic asthma. Cross-linking by allergen of IgE bound to several cell types via highaffinity (FceRI) or low-affinity receptors (FceRII) initiates an inflammatory cascade triggering cell activity and the release of inflammatory mediators, which contribute 
Fig. 5. Changes in $\mathrm{FEV}_{1}$ during omalizumab (a) or conventional (b) therapy without omalizumab. ------- = Results obtained in 2 patients identified as nonresponders.

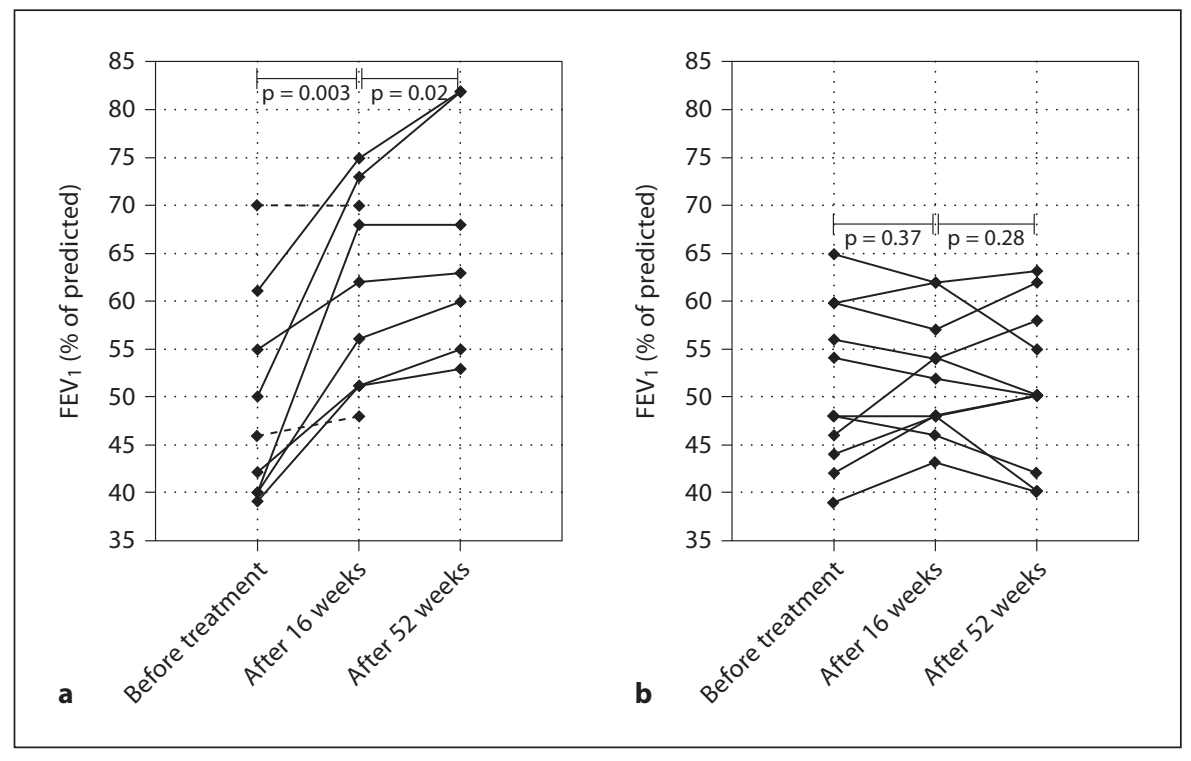

Table 2. Correlations between changes in the studied parameters after 16 and 52 weeks of therapy in the omalizumabtreated group

\begin{tabular}{|c|c|c|c|c|c|c|c|c|}
\hline & \multicolumn{2}{|c|}{$\mathrm{FE}_{\mathrm{NO}}$} & \multicolumn{2}{|l|}{ ECP } & \multicolumn{2}{|l|}{ Eos } & \multicolumn{2}{|c|}{$\mathrm{FEV}_{1}$} \\
\hline & $\mathrm{r}$ & $\mathrm{p}$ & $\mathrm{r}$ & $\mathrm{p}$ & $\mathrm{r}$ & $\mathrm{p}$ & $\mathrm{r}$ & $\mathrm{p}$ \\
\hline \multicolumn{9}{|c|}{ Changes after 16 weeks } \\
\hline ET-1 & 0.89 & 0.001 & 0.79 & 0.01 & 0.78 & 0.01 & -0.65 & 0.07 \\
\hline $\mathrm{FE}_{\mathrm{NO}}$ & & & 0.63 & 0.04 & 0.69 & 0.03 & -0.55 & 0.12 \\
\hline ECP & & & & & 0.79 & 0.01 & -0.46 & 0.2 \\
\hline Eos & & & & & & & -0.52 & 0.13 \\
\hline \multicolumn{9}{|c|}{ Changes after 52 weeks } \\
\hline ET-1 & 0.79 & 0.03 & 0.71 & 0.07 & 0.59 & 0.16 & -0.15 & 0.74 \\
\hline $\mathrm{FE}_{\mathrm{NO}}$ & & & 0.41 & 0.36 & 0.40 & 0.37 & -0.37 & 0.41 \\
\hline $\mathrm{ECP}$ & & & & & 0.92 & 0.003 & -0.18 & 0.73 \\
\hline Eos & & & & & & & -0.45 & 0.30 \\
\hline
\end{tabular}

Eos $=$ Eosinophils to mucosal inflammation, bronchial hyperresponsiveness and airway remodeling $[17,18]$.

The biological activity of IgE is mainly connected with mast cell activation [19]. Mast cells are involved in the accumulation of inflammatory cells, mucosal inflammation, endothelial activation and bronchial hyperresponsiveness [19]. These actions are closely associated with the secretion of cytokines such as Th2 cytokines including interleukins 4 and 5 (IL-4, IL-5), tumor necrosis factor- $\alpha$ (TNF- $\alpha$ ), and ET-1 [19]. Mast cells could modulate airway remodeling through release of cytokines, chemokines and growth factors; they could also influence many intercellular interactions and lead to chronic asthma [20].

The mechanisms underlying the clinical efficacy of omalizumab are not fully understood. However, the spectrum of anti-inflammatory actions of anti-IgE treatment extends from the limitation of $\operatorname{IgE}$ action on effector cells (e.g. mast cells and basophils), including a combination of reduced free IgE levels and IgE receptor downregulation and an inhibition of the accumulation of inflammatory cells in the lungs, to a reduction in the release of Th2 cytokines [2]. 
Table 3. Correlations between changes in the studied parameters after 16 and 52 weeks of therapy in the group of patients not treated with omalizumab

\begin{tabular}{|c|c|c|c|c|c|c|c|c|}
\hline & \multicolumn{2}{|c|}{$\mathrm{FE}_{\mathrm{NO}}$} & \multicolumn{2}{|l|}{ ECP } & \multicolumn{2}{|l|}{ Eos } & \multicolumn{2}{|c|}{$\mathrm{FEV}_{1}$} \\
\hline & $\mathrm{r}$ & $\mathrm{p}$ & $\mathrm{r}$ & $\mathrm{p}$ & $\mathrm{r}$ & $\mathrm{p}$ & $\mathrm{r}$ & $\mathrm{p}$ \\
\hline \multicolumn{9}{|c|}{ Changes after 16 weeks } \\
\hline ET-1 & 0.30 & 0.4 & 0.28 & 0.42 & -0.04 & 0.89 & -0.02 & 0.9 \\
\hline $\mathrm{FE}_{\mathrm{NO}}$ & & & 0.4 & 0.24 & 0.58 & 0.08 & 0.29 & 0.4 \\
\hline ECP & & & & & 0.6 & 0.05 & -0.38 & 0.26 \\
\hline Eos & & & & & & & 0.02 & 0.95 \\
\hline \multicolumn{9}{|c|}{ Changes after 52 weeks } \\
\hline ET-1 & 0.33 & 0.35 & 0.32 & 0.34 & -0.2 & 0.57 & -0.42 & 0.22 \\
\hline $\mathrm{FE}_{\mathrm{NO}}$ & & & 0.03 & 0.9 & 0.11 & 0.75 & 0.09 & 0.8 \\
\hline $\mathrm{ECP}$ & & & & & 0.08 & 0.82 & 0.18 & 0.6 \\
\hline Eos & & & & & & & 0.19 & 0.58 \\
\hline
\end{tabular}

Eos $=$ Eosinophils
The clinical efficacy and anti-inflammatory effect of anti-IgE therapy with omalizumab in patients with asthma has been confirmed in many clinical trials $[3,19,21$, 22]. Massanari et al. [23], in a pooled analysis including data from five randomized trials, demonstrated that the reduction of serum free IgE by omalizumab is associated with a significant reduction in peripheral eosinophil counts in allergic patients with asthma. The decrease in $\mathrm{FE}_{\mathrm{NO}}$ during omalizumab therapy was previously described by Silkoff et al. [24]. In our study, we observed a statistically significant decrease in parameters relating to eosinophilic airway inflammation and $\mathrm{FE}_{\mathrm{NO}}$. The reduction in $\mathrm{FE}_{\mathrm{NO}}$ indicates that omalizumab inhibits eosinophilic airway inflammation. We found a statistically significant increase in $\mathrm{FEV}_{1}$. In large trials, the main effect of omalizumab was a reduction in acute exacerbations with little change in lung function parameters. However, in the INNOVATE trial, Humbert et al. [25] demonstrated that $\mathrm{FEV}_{1}$ was significantly improved with omalizumab compared with a placebo at study completion. In our opinion, the improvement in $\mathrm{FEV}_{1}$ observed in our study is a consequence of the anti-inflammatory efficacy of omalizumab therapy in those patients in whom such improvement was possible.

In omalizumab-treated patients, higher - but not statistically significantly higher - levels of the parameters used in the assessment of eosinophilic inflammation were observed. In the authors' opinion, this is mainly related to the small group size of patients and the presence of higher values in 3 patients in the omalizumab-treated group. However, the authors suggest that this does not change the essential results and conclusions of the study.
The main objective of this study was to compare changes of ET-1 in EBC during omalizumab treatment and those, if any, in the conventionally treated group. The difference in the initial values of the studied parameters does not seem to have influenced the observed changes and conclusions.

Analysis of the effect of this kind of treatment on the activity and interactions of many inflammatory cells and their ability to release many proinflammatory cytokines and mediators suggests that long-term therapy with omalizumab could have a beneficial effect on limiting the development of bronchial structural changes $[2,9]$. Until now, only a few published studies have assessed the effect of omalizumab on bronchial remodeling $[2,9]$. There are no data concerning the effect of anti-IgE therapy on ET-1 expression in the airways.

In the airways, ET-1 is found mainly in the bronchial epithelium [26]. The increased expression of ET-1 at this site is observed in asthma and is correlated with the severity of the disease [27]. ET-1 is also synthesized by inflammatory cells, such as macrophages [28] and mast cells [29], as well as by vascular endothelial cells [5].

There are many reports concerning interactions between ET-1 and other cytokines essential in asthma. TNF- $\alpha$ stimulates ET-1 release from cultured bronchial smooth muscle cells [30]. Xu et al. [30] have shown that ET-1 can induce the expression of granulocyte-macrophage colony-stimulating factor (GM-CSF) in human lung fibroblasts and, as a consequence, could directly affect eosinophil infiltration into the airways. ET-1 also evokes the release of GM-CSF, IL-6, IL-8, IL-1, TNF- $\alpha$, and TGF- $\alpha$ from monocytes [31]. The cooperation of 
ET-1 and other cytokines that are growth factors for bronchial subepithelial myofibroblasts could play a crucial role in airway remodeling which is the consequence of repeated episodes of epithelial damage and repair in asthmatic inflammation [32].

ET-1 may be involved in airway remodeling by reducing epithelial cell migration and inducing the proliferation of airway smooth muscle cells and fibroblasts. It has also been suggested that ET-1 may contribute to slow down repair mechanisms of asthmatic airway damage caused by environmental agents and allergens [33].

He et al. [34] have demonstrated that in patients with severe asthma who had a poor response to inhaled corticosteroids, ET-1 expression in the bronchial mucosa was still high. The authors suggest that airway hyperresponsiveness in patients with severe asthma could be associated with increased ET-1 expression.

Being simple and noninvasive, EBC examination could be exploited to detect specific levels of biomarkers and monitor disease severity in response to appropriate prescribed therapy. Good reproducibility in EBC volume and mediator concentration of several markers, such as $\mathrm{pH}, \mathrm{H}_{2} \mathrm{O}_{2}$, adenosine, 8-isoprostane, was demonstrated $[14,35]$. In our previous report [36], we showed that measurements of ET-1 in EBC of asthmatic patients may provide another useful diagnostic tool for detecting and monitoring inflammation, disease severity and response to treatment.

The results of our study indicate that during anti-IgE therapy with omalizumab in asthmatic patients with persistent severe disease, a decrease in airway ET-1 expression is observed.

The mechanisms by which omalizumab decreases airway ET-1 expression have not been specifically investigated, but could involve the inhibition of mediators (such as TNF- $\alpha$, platelet-derived growth factor, transforming growth factor- $\beta$ ) and cytokine (IL-1 $\beta$, IL-6) release by mast cells, which increase ET-1 expression on bronchial epithelial and vascular endothelial cells, as well as a direct decrease in ET-1 secretion by mast cells.

In 2 patients considered as nonresponders, we did not obtain a decrease in ET-1 in EBC, or in other studied parameters. This could suggest that the beneficial clinical effect of omalizumab treatment may also be associated with downregulation of ET-1 in the airways.

This study has some limitations. An important weakness is that it was an open-label study, not randomized, without placebo control. The next limitation is the small number of studied patients. Another weak point could concern the diagnostic methods used in the study. The analysis of EBC is still in the experimental phase. Many questions concerning the lack of standardization for both the collection and analysis of EBC, and the effect of many factors on the concentrations of EBC markers are still not answered. More studies are needed to confirm the beneficial effect of anti-IgE therapy on airway remodeling in asthmatic patients.

\section{Conclusions}

Downregulation of ET-1 in EBC significantly correlates with a decrease in the markers of allergic, particularly eosinophilic, inflammation, such as $\mathrm{FE}_{\mathrm{NO}}$, ECP or blood eosinophil count, as well as improving spirometric indices. These changes were observed after 16 weeks of therapy. The follow-up observation performed after 52 weeks of treatment revealed a further, very significant, fall in ET-1 concentrations in EBC; however, the improvement of other markers of allergic inflammation were less pronounced. This could indicate that anti-IgE therapy has a great - and achievable - influence on eosinophilic inflammation during the first 16 weeks of therapy. On the other hand, the effects of many other immunological mechanisms related to remodeling, as well as with the action and interactions of ET-1, already observed in the first period of treatment, significantly develop over time. This is a very important observation that suggests that longterm anti-IgE therapy with omalizumab in asthmatic patients could significantly limit the development of inflammation and bronchial structural changes.

\section{Acknowledgements}

This work was supported by research grant No. 3-06732P from the Medical University of Bialystok, Poland. The authors would like to thank all the study participants.

References

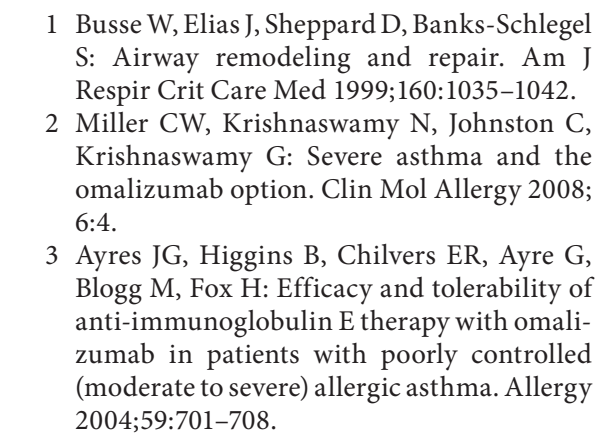

Respiration 2010;80:534-542 
4 Hamelmann E: The rationale for treating allergic asthma with anti-IgE. Eur Respir Rev 2007; 16:61-66.

-5 Yanagisava M, Kurihara S, Kurima Y: A novel potent vasoconstrictor peptide produced by vascular endothelial cells. Nature 1988; 332:411-415.

-6 Mattoli S, Mezzetti M, Riva G, Allegra L, Fasoli A: Specific binding of endothelin on human bronchial smooth muscle cells in culture and secretion of endothelin-like material from bronchial epithelial cells. Am J Resp Cell Mol Biol 1990;3:103-108.

7 Luscher TF: Endothelin. J Cardiovasc Pharmacol 1992;18:15-22.

$\checkmark 8 \mathrm{Xu}$ J, Zhong NS: Mechanisms of bronchial hyperresponsiveness: the interaction of endothelin-1 and other cytokines. Respirology 1999;4:413-417.

$\checkmark 9$ Huang YC, Leyko B, Frieri M: Effects of omalizumab and budesonide on markers of inflammation in human bronchial epithelial cells. Ann Allergy Asthma Immunol 2005; 95:443-451.

10 Global Initiative for Asthma. Global strategy for asthma management and prevention: NHLBI/WHO Report 2006; publication 023569.

-11 Hochhaus G, Brookman L, Fox H, Johnson C, Matthews J, Ren S, Deniz Y: Pharmacodynamics of omalizumab: implications for optimized dosing strategies and clinical efficacy in the treatment of allergic asthma. Curr Med Res Opin 2003;19:491-498.

$\checkmark 12$ American Thoracic Society/American Lung Association recommendations for on-line measurement of exhaled nitric oxide in adults and the recommendations for on-line, offline and nasal expired nitric oxide measurements in children. Am J Respir Crit Care Med 1999;160:2104-2117.

13 American Thoracic Society: Lung function testing: selection of reference values and interpretative strategies. Am Rev Respir Dis 1991;144:1202-1218.

14 Horvath I, Hunt J, Barnes PJ: Exhaled breath condensate: methodological recommendations and unresolved questions. Eur Respir J 2005;26:523-548.

15 Rahman I, Biswas S: Non-invasive biomarkers of oxidative stress: reproducibility and methodological issues. Redox Rep 2004;9: 125-143.

16 Multu GM, Garey KW, Robbins RA, Danziger LH, Rubinstein I: Collection and analysis of exhaled breath condensate in humans. Am Respir Crit Care Med 2001;164:731-737.
17 Hanf G, Brachmann I, Kleine-Tebbe J, Seybold J, Kunkel G, Suttorp N, Noga O: Omalizumab decreased IgE-release and induced changes in cellular immunity in patients with allergic asthma. Allergy 2006;61:11411144.

18 Platts-Mills TA: The role of immunoglobulin E in allergy and asthma. Am J Respir Crit Care Med 2001;164:1-5.

19 Djukanovic R, Wilson SJ, Kraft M, Jarjour NN, Steel M, Chung KF, Bao W, Fowler-Taylor A, Matthews J, Busse WW, Holgate ST, Fahy JV: Effects of treatment with anti-immunoglobulin E antibody omalizumab on airway inflammation in allergic asthma. Am J Respir Crit Care Med 2004;170:583-593.

20 Okayama Y, Ra C, Saito H: Role of mast cells in airways remodeling. Curr Opin Immunol 2007;19:687-693.

21 Brusselle G, Michils A, Louis R, Dupont L, Van de Maele B, Delobbe A, Pilette C, Lee CS, Gurdain S, Vancayzeele S, Lecomte P, Hermans C, MacDonald K, Song M, Abraham I: 'Real-life' effectiveness of omalizumab in patients with severe persistent allergic asthma: The PERSIST study. Respir Med 2009;103. 1633-1642.

22 Holgate S, Buhl R, Bousquet J, Smith N, Panahloo Z, Jimenez P: The use of omalizumab in the treatment of severe allergic asthma: a clinical experience update. Respir Med 2009; 103:1098-1113.

23 Massanari M, Holgate ST, Busse WW, Jimenez P, Kianifard F, Zeldin R: Effect of omalizumab on peripheral blood eosinophilia in allergic asthma. Respir Med 2010; 104:188-196.

24 Silkoff PE, Romero FA, Gupta N, Townley RG, Milgrom $\mathrm{H}$ : Exhaled nitric oxide in children with asthma receiving Xolair (omalizumab), a monoclonal anti-immunoglobulin E antibody. Pediatrics 2004;113:308-312.

25 Humbert M, Beasley R, Ayres J, Slavin R, Hebert J, Bousquet J, Beeh KM, Ramos S, Canonica GW, Hedgecock S, Fox H, Blogg M, Surrey K: Benefits of omalizumab as add-on therapy in patients with severe persistent asthma who are inadequately controlled despite best available therapy (GINA 2002 step 4 treatment): INNOVATE. Allergy 2005;60 309-316

26 Redington AE, Springall DR, Meng QH, Tuck AB, Holgate ST, Polak JM, Howarth PH: Immunoreactive endothelin in bronchial biopsy specimens: increased expression in asthma and modulation by corticosteroid therapy. J Allergy Clin Immunol 1997;100: $544-552$.
27 Redington AE, Springall DR, Ghatei MA, Lau LC, Bloom SR, Holgate ST, Polak JM, Howarth PH: Endothelin in bronchoalveolar lavage fluid and its relation to airflow obstruction in asthma. Am J Respir Crit Care Med 1995;151:1034-1049.

28 Ehrenreich HR, Anderson CH, Fox P, Rieckmann P, Hoffman GS, Travis WD, Coligan JE, Kehrl JH, Fauci AS: Endothelins, peptides with potent vasoactive properties, are produced by human macrophages. J Exp Med 1990;172:1741-1748.

29 Ehrenreich HR, Bur M, Rottem L, Hültner L, Hylton JB, Garfield M, Coligan JE, Metcalfe DD, Fauci AS: Endothelins belong to the assortment of mast cell-derived and mast cellbound cytokines. New Biol 1991;4:147-151.

$30 \mathrm{Xu}$ J, Zhong NS: The interaction of tumor necrosis factor- $\alpha$ and endothelin-1 in pathogenic models of asthma. Clin Exp Allergy 1997;27:568-573.

31 Cunningham ME, Huribal M, Bala RJ, McMillen MA: Endothelin-1 and endothelin-4 stimulate monocyte production of cytokines. Crit Care Med 1997;25:958-964.

$>32$ Zhang S, Smartt H, Holgate ST, Roche WR: Growth factors secreted by bronchial epithelial cells control myofibroblasts proliferation: an in vitro co-culture model of airway remodeling in asthma. Lab Invest 1999;79: 395-405.

-33 Dosanjh A, Zuraw B: Endothelin-1 (ET-1) decreases human bronchial epithelial cell migration and proliferation: implications for airway remodeling in asthma. J Asthma 2003;40:883-886.

>34 He W-G, Xu J, Zhong NS: Effect of inhaled corticosteroids on the mRNA expressions of endothelin-1 and endothelin converting enzyme in bronchial asthma. Chinese J Tubercul Respir Dis 1998;21:336-241.

-35 Matsunaga K, Ichikawa T, Yanagisawa S, Akamatsu K, Koari A, Hirano T, Sugiura H, Minakata Y, Ichinose M: Clinical application of exhaled breath condensate analysis in asthma: prediction of $\mathrm{FEV}_{1}$ improvement by steroid therapy. Respiration 2009;78:393398.

36 Zietkowski Z, Skiepko R, Tomasiak MM, Bodzenta-Lukaszyk A: Endothelin-1 in exhaled breath condensate of stable and unstable asthma patients. Respir Med 2008;102: 470-474. 